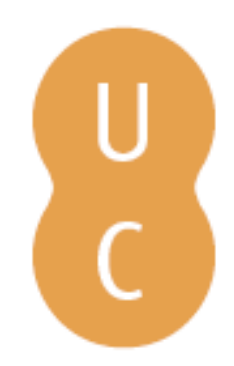

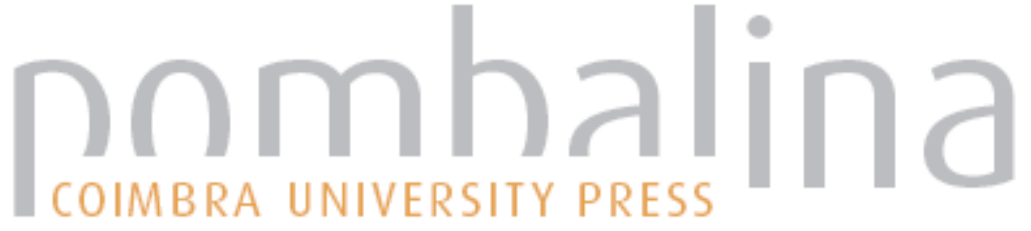

\section{Encerramento do colóquio "As três religiões do livro"}

Autor(es): $\quad$ Sampaio, Jorge

Publicado por: Imprensa da Universidade de Coimbra

URL

persistente: URI:http://hdl.handle.net/10316.2/30091

DOI: $\quad$ DOI:http://dx.doi.org/10.14195/978-989-26-0310-0_10

Accessed : $\quad$ 26-Apr-2023 09:08:04

A navegação consulta e descarregamento dos títulos inseridos nas Bibliotecas Digitais UC Digitalis, UC Pombalina e UC Impactum, pressupõem a aceitação plena e sem reservas dos Termos e Condições de Uso destas Bibliotecas Digitais, disponíveis em https://digitalis.uc.pt/pt-pt/termos.

Conforme exposto nos referidos Termos e Condições de Uso, o descarregamento de títulos de acesso restrito requer uma licença válida de autorização devendo o utilizador aceder ao(s) documento(s) a partir de um endereço de IP da instituição detentora da supramencionada licença.

Ao utilizador é apenas permitido o descarregamento para uso pessoal, pelo que o emprego do(s) título(s) descarregado(s) para outro fim, designadamente comercial, carece de autorização do respetivo autor ou editor da obra.

Na medida em que todas as obras da UC Digitalis se encontram protegidas pelo Código do Direito de Autor e Direitos Conexos e demais legislação aplicável, toda a cópia, parcial ou total, deste documento, nos casos em que é legalmente admitida, deverá conter ou fazer-se acompanhar por este aviso.

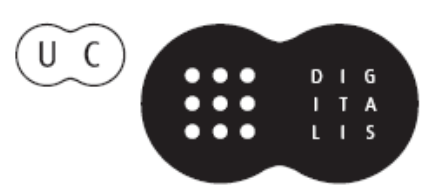




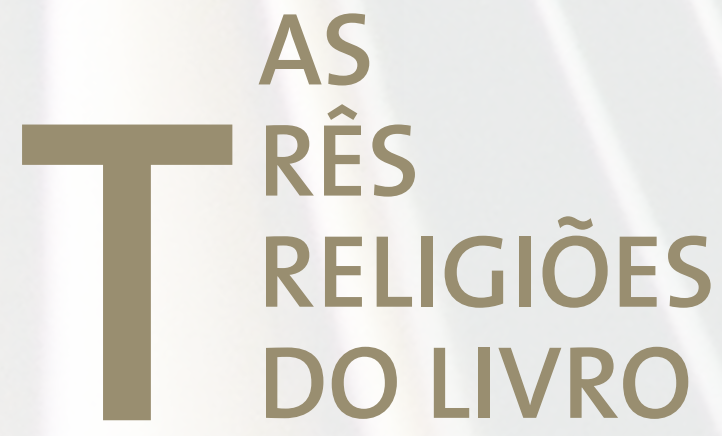

Anselmo Borges

João Gouveia Monteiro

COORDENAÇÃO 
Jorge Sampaio ${ }^{26}$

\section{ENCERRAMENTO DO COLÓQUIO \\ “ASTRES RELIGIÕES DO LIVRO”}

\section{Excelências,}

Minhas Senhoras e Senhores:

Foi com muito prazer que aceitei o amável convite que me foi dirigido para participar no encerramento deste Colóquio Internacional dedicado ao tema candente do que se poderia chamar o "monoteísmo mediterrânico", para utilizar a expressão feliz de um pensador norte-americano, William Pfaff numa obra recente (The Irony of Manifest Destiny: the Tragedy of America's Foreign Policy).

Num tempo em que as religiões estão de volta à ágora, na acepção grega de espaço público e de debate político, ou se se preferir numa época cada vez mais marcada pelo ressurgimento da "questão religiosa", não só no plano interno aos Estados, mas também no quadro da política internacional, é importante impulsionar o diálogo inter-religioso e repensar a religião como facto de sociedade que coexiste com outras crenças e convicções que até podem ser não religiosas.

A este respeito, quero lembrar aqui a Declaração de Durban, adoptada pela polémica Conferência Mundial de combate ao racismo, discriminação racial, xenofobia e intolerância correlata, que claramente reconhece o papel central que a "religião, a espiritualidade e as crenças desempenham nas vidas de milhões de homens e mulheres e no modo como vivem e tratam as outras pessoas".

\footnotetext{
26 Alto Representante das Nações Unidas para a Aliança das Civilizações.
} 
A mesma Declaração reconhece também que "as religiões podem e devem contribuir para a promoção da dignidade e dos valores inerentes à pessoa humana, bem como para a erradicação do racismo, discriminação racial, xenofobia e intolerância correlata" (Declaração de Durban).

Por que refiro este texto?

Apenas para servir de introdução ao ponto de vista que a iniciativa das Nações Unidas da Aliança das Civilizações privilegia em relação à questão das religiões e do diálogo inter-religioso, que é a abordagem que quero desenvolver aqui hoje.

Minhas Senhoras e Senhores:

Em três pinceladas, para aqueles que o não sabem, a Aliança das Civilizações é uma iniciativa das Nações Unidas, lançada por Espanha e pela Turquia em 2005, mas que conta hoje com uma comunidade de apoio de mais de cento e vinte membros, entre países - cerca de uma centena e organizações internacionais.

Lançada num tempo em que as teses de Huntington sobre o choque de civilizações eram predominantes e em que o 11 de Setembro e os atentados que se lhe seguiram pareciam dar razão à guerra global contra o terror, a Aliança das Civilizações foi criada precisamente para fomentar o reatamento do diálogo entre culturas e religiões, conciliar visões do mundo diferentes e, sobretudo, favorecer a criação de pontes entre as sociedades ditas ocidentais e as muçulmanas, restabelecendo os intercâmbios e o diálogo inter-religioso e intercultural entre elas.

A Aliança das Civilizações correspondeu, assim, ao desenvolvimento de uma perspectiva de soft power da segurança e da paz no seio das Nações Unidas destinada a servir de contrapeso à guerra global contra o terrorismo, o qual, no imaginário popular de muitos povos, acabou por ser abusivamente assimilado ao Islão, levando a amálgamas de toda a espécie e, sobretudo, ao inequívoco aumento da intolerância, da discriminação e dos preconceitos com base na religião professada.

Note-se também, não como circunstância atenuante mas em abono da verdade, que a intolerância no seio do próprio Islão, o aumento das 
tensões e da violência entre as suas várias facções e comunidades e o fraco grau de integração de minorias religiosas que se regista em muitos países de maioria muçulmana, dando tantas vezes origem a atentados terroristas quase quotidianos, não têm, também, sido propícios a que o diálogo inter-religioso, a apreciação mútua e a coexistência harmoniosa se desenvolvam.

Por isso é que é tão necessário que cada civilização, cada religião e cada cultura sejam capazes de praticar, no seu próprio interior, a tolerância, o reconhecimento da liberdade de consciência e o direito à diferença.

Não só porque a intolerância de uma cultura ou de uma religião é proporcional à intolerância no seu próprio interior, mas também porque a intolerância de uma cultura ou de uma religião não é estável, mas tem variado ao longo dos tempos.

Sabemos, claro, que a história das nações, das religiões e das civilizações tem alternado períodos de paz e de guerras, momentos de afrontamento, conflitos e intolerâncias com vontade de diálogo, abertura ao Outro e à cultura da diferença, da tolerância e de valores universalistas.

Por outro lado, é verdade que as culturas tendem muitas vezes a afirmar as respectivas identidades no confronto com as outras. E os particularismos culturais, legitimados por factores religiosos ou étnicos, têm funcionado como vectores de conflito e de dominação.

Entendo, por isso, e insisto neste ponto, que o diálogo, complexo e exigente, de civilizações, culturas e religiões é necessário, possível e frutuoso. É o melhor contraponto para o isolamento, a desconfiança e o confronto, mas também o mais potente incentivo à abertura, ao entendimento e à tolerância .

Sem dúvida, a História mostra-nos que este não é um diálogo fácil. Mas se não for ensinado e cultivado, cede o lugar ao monólogo ou ao mutismo, que são quase sempre fermento de perigosas atitudes extremistas e de pulsões fanáticas.

Por isso, também, a minha convicção é que a Aliança das Civilizações é a iniciativa certa, no momento certo. Daí, digamos, o meu optimismo.

Para terminar esta brevíssima apresentação da Aliança das Civilizações, lembro apenas que são quatro os seus principais campos de actuação: a educação, os jovens, os media e as migrações. 
Para operacionalizar os seus objectivos, a Aliança promove a elaboração de planos nacionais para o diálogo e a cooperação intercultural e de estratégias regionais. Por outro lado, através das suas redes de parceiros, procura apoiar o desenvolvimento de iniciativas e projectos no terreno por forma a estimular a boa governação da diversidade cultural, enquanto quarto pilar do desenvolvimento sustentável e dimensão humana da paz, como gosto de dizer.

Minhas Senhoras e Senhores:

Gostaria agora de terminar com algumas reflexões sobre o diálogo entre as três "religiões do livro", para parafrasear o título do vosso colóquio.

E gostaria de começar por referir que ainda na semana passada, em Malta, foi aprovada a Estratégia Regional da Aliança das Civilizações para o Mediterrâneo, que identifica quatro objectivos e dez prioridades de acção para esta área crítica do mundo, em que precisamente nasceram os três monoteísmos, que tanto a têm marcado e que continuam a pesar sobre o seu futuro.

Não só porque o Mediterrâneo representa simultaneamente o seu centro de convergência e o seu ponto de fuga, mas também porque as sociedades que compõem esta região, que alguns chamam de Euro-Mediterrânica, mantêm entre si grandes desníveis e desigualdades, apartadas que estão por clivagens fundas em termos políticos, sociais, económicos, culturais e religiosos.

Por isso, a meu ver, é também nesta região do mundo que a necessidade de diálogo inter-religioso é mais forte, onde ela pode ser mais profícua e onde os resultados podem ser, também, mais espectaculares.

O diálogo inter-religioso é uma componente importante da prevenção e transformação de conflitos e pode mesmo desempenhar um papel importante na sua resolução.

Peguemos no exemplo complexíssimo de Jerusalém - alguém alguma vez poderá imaginar uma solução duradoura para a cidade das três religiões à revelia destas, fazendo delas tábua rasa ou deixando-as de fora? Eu, pessoalmente, não acredito.

Peguemos no caso das minorias religiosas. Com mais diálogo inter-religioso, mais concertação entre poderes públicos e actores religiosos, 
não obteríamos uma melhor solução para a sua integração e para uma nova definição do pluralismo religioso?

Meus caros amigos:

É deste ponto de vista que a Aliança apoia e estimula as iniciativas de diálogo inter-religioso. Não como forma de debate teológico, que esse é para os teólogos. Não como forma de debate metafísico sobre a verdade revelada. Mas apenas como encontro entre visões do mundo em que os consensos são possíveis, porque os pontos comuns em relação a concepções fundamentais sobre o mundo, o homem e a vida são suficientemente sólidos, consistentes e concordantes.

Por isso, é possível construir um diálogo e agir de concerto com base em plataformas de entendimento que urge explorar e desenvolver, sempre, cada vez mais.

A este respeito, quero referir duas iniciativas de especial relevância.

A primeira é da autoria de Karen Armstrong, que foi membro do grupo que redigiu o relatório fundador da Aliança das Civilizações. No centro da iniciativa está a Carta da Compaixão, que enumera um conjunto de princípios comuns às três religiões monoteístas, mas susceptíveis de serem subscritos por outras religiões e crenças. Fundamenta-se no conceito da "compaixão", que vai muito para além da acepção comum de "dó" ou "pena" do outro. De facto, na feliz expressão do teólogo católico Leonardo Boff, compaixão traduz a capacidade de ir ao encontro do outro, de se pôr no lugar do outro, de partilhar as suas alegrias ou tristezas, de compreender os seus pontos de vista.

A segunda iniciativa é mais recente e foi objecto de uma Resolução da Assembleia Geral das Nações Unidas há uma semanas atrás. Visa a organização, com carácter anual, de uma "semana da harmonia inter-religiosa"- a primeira de cada mês de Fevereiro - inspirada no "amor de Deus e do próximo" e/ou do "Bem e do próximo", dois mandamentos que, sob uma ou outra forma, unem a humanidade.

As actividades a empreender podem revestir as mais diversas formas desde cerimónias conjuntas a sessões de diálogo inter-religioso, ou ainda a confraternizações conjuntas - sob a unidade da mensagem a transmitir. 
Gostaria de deixar aqui um apelo a que, entre nós, se possa organizar um programa de actividades que poderíamos publicitar no site criado para o efeito. Pela minha parte, reitero a disponibilidade do meu gabinete em coordenar tal programa comum.

É uma sugestão que deixo aqui e com a qual encerro este colóquio.

Muito obrigado 